\title{
Vocabulary Teaching in Distance Learning
}

\author{
Yingling $\mathrm{Gu}$ \\ Changji Radio and Television University, China \\ Email: gylroom@sina.cn
}

\begin{abstract}
Word is the basic function unit and foundation of English language. The ignorance of word memorization will make English study the water without a source. English vocabulary teaching is an important part of English teaching. In some way, foreign language ability of students depends on the vocabulary they mastered. the word insufficiency or inaccurateness is "the biggest obstacle" for students to study English. Therefore, it is the extremely important task for a teacher to scientifically enlarge students' vocabulary according to the English new curriculum standard and the rules of memorization.
\end{abstract}

Index Terms - vocabulary teaching, five steps, oblivion

\section{INTRODUCTION}

Words are the basic functional unit of English language, which is its foundation and ignore the vocabulary of memory. Learning English will become like non-existent. As an English teacher, I've noticed some good ways and bad ways of English teaching and learning. In my daily English teaching I think how to make students remember words faster and more prison? Students' vocabulary memory efficiency is placed in front of each teacher topic. Many experts have got many achievements in this topical research and summarizes some vocabulary method. Although the students grasp a lot of memory methods, but in most of the time learning effect is not very ideal, the main reason is that students remember vocabulary's attitude, which is passive, YiBaoShiHan, they assault the words by pre-exam.They have remembered many ripe words when using either can not recall, either error-prone. Every time they complain too many new words and cannot comprehend, their tests are always not good enough.

The Well-known psychologist named Hermann Ebbinghaus is from German, he thinks that person's memory is a certain rule forgotten process, which is occurring disequilibrium, after memorizing initial forgotten faster, but as time goes on, people's forgotten by fast to slow and end up basic not forgotten. According to this law, in order to prevent forgotten, improving memory effect, they should be timely review, instead, they have forgotten to go over and remember them again. Unless they review in time, their aims avoid forgotting.

Through many years' teaching experience, the author thinks that English teaching is the key to a teaching method, she has been engaged in English teaching for a long time as the teacher. Generally speaking, English learning consists of five aspects: listening, speaking, reading, writing and translating. And the basis for the skills, in my point of view , lies in a good mastery of vocabulary, for vocabulary is an essential component of a language, without vocabulary, nothing can be expressed. Firstly, let's have a look at English classes in China. There are five teaching methodologies practised already. Step One: language input, teacher can use multimedia and show demonstration means such as let students spell words and through reading articles to experience new words in language in the text. Step Two: language internalization, the teacher makes students use reading in class, students understand words application and further feeling language in the text, the teacher is to have guidance and assistance summary. The teacher will set exercises, design words application context, translate the sentence exercises and help students to internalize the target language form. Step Three: language output, focused on writing, the students themselves write applications context what they have learned. Step Four: resistance to forget to review, weekly quizzes and exams supervise monthly exam. Step Five: midterm exam, the final exam. Supervise the student to review.

\section{Plan IMPLEMENTATion Steps}

\section{A. Step 1, Language Input}

(1) Figural memories - pronunciation and spelling

Pronunciation aspects:

Phonetics teaching should be mainly by imitating, teachers should provide lots of listening, imitating and practice opportunities, helps the students to grasp the phonetic rules.

Spelling:

Through mastery of word aloud. then rules and pronunciation rules and strengthen the students for words of the memory. On this link, pay attention to letters, letters combin in words, pronunciation, spelling and pronunciation rules according to spelling words of teaching, raises student's spelling.

(2) Explanation in the language text, then in the context of memorizing words

Many linguists research shows that: the first language learner's vocabulary knowledge comes from mostly extensive 
reading, visible, in the context of vocabulary learning vocabulary is the main way of natural acquisition. Therefore, the teacher should attach importance to cultivating students' infer the meaning in context, which requires the teachers' ability to choose a suitable context professor vocabulary material, and as far as possible in the context of the present vocabulary.

(3) The teacher presented to expand their language material to let the students summarize the comparative induction.

Ex. : add

All Numbers add up to 125 nowadays.

Add all the Numbers up and so on has on the.

Students from these language materials concludes "add" usage. In concrete contextual guess the phrase and the meaning of the word, on the one hand, the teacher lets the students learn the words from the context, on the other hand, to cultivate students guess the meaning of the new words, then the teacher makes a final ability summary.

\section{B. Step 2, Language Internalization - Context Drill}

In English vocabulary teaching, many experts agreed that "word is not departed from group, the group of words are not from away sentences, sentences are not from section." This fully embodies the context in the role of memorizing words. Otherwise, on the one hand, memory is only shallow, memory in-depth, on the other hand, no context even memory many words cannot apply it.

Practice design

Ex. :

He___ to correct the achievements, and correct the mistakes.

Li Ming tried to tell her but she (up to ignore) me.

She was (uneasy) when she heard the news.

The bad lady c___ the young beautiful girl into the belief that she was her mother.

His friends has s__ from ill health for some years.

\section{Step 3, Language Output}

Teacher's task not only stay in students to constantly input new vocabularies and consolidate vocabularies,too, and teachers create opportunities application memory vocabulary for learners, also is to let the students have the opportunity to language output, namely, written and said, language output is an important step of vocabulary learning, if they are not used correctly understanding of words, so, these vocabulary is only your receiving vocabulary, not output vocabulary, also cannot say fully mastered these words. The output of language materials for students, teachers can use the appropriate way for students to deepen understanding, error correction, consolidated the memory, and make students truly master what they have learnt, they can achieve the purpose of enlarge their vocabularies. Translate the sentence, make conversations, written discourse application context (the higher stage of consolidating exercises), etc.

\section{Step 4, Week Unit Vocabulary Test Detection and Consolidate Learning Effect}

In the weeks' practice, the teacher is sure to formulate corresponding about lexical exercises to detect the study effect. The teacher must supervise students on lexical again reappearance, in recognition of repeat let students subtle, melt touch to words of air. This aims to change the students "YiBaoShiHan", the drawbacks are unstable and not thorough, which assault vocabulary memory. The teacher should make students form good memory according to forget law habits.

Weeks necessary practice design.

Spelling words and phrases translation

To get as much as information as possible we should learn to c 1 do survey 2. add up to 3.put up with_

\section{E. Step 5, Test Detection and Supervise Students Repeatedly Representation Vocabulary}

The new with old, the old with new. Knowledge is both new and old relation to deepen our understanding and memory. Therefore, in vocabulary teaching should be first catch characteristics of words, according to the word meaning, parts of speech, words sound, morphological characteristics, word-building classification comparison and differentiate the induction, learn new league old, overall expansion, old and new vocabulary integration, improving recreate rate, lexical processing, making use of all sorts of learning skills, encouraging form independent strategy. According to Hermann Ebbinghaus' law forgotten to mobilize students' initiative kept for resistance to forget the emersion of revision. On total review, midterm total review and the final total review as an opportunity. Let students resistance to forget constantly struggle.

\section{F. $\quad$ Step 6, Computer-assisted Aids.}

Computer-assisted aids. This includes two parts, visually, and audio. We can use power point or flash to show a certain situation and tell students the meaning of some words which are difficult for us to explain by using language. Secondly, the teacher may use the tape-recording together with this one. By using this aid, we may "help to get rid of the learners' boredom with language learning. Help to drive away the learners' nervousness. To arouse the learners' 
motivations. To help the learner to concentrate on learning" (Liu Juan 2007 ).

The most important part of vocabulary teaching is to help students memorize the words. Then, the author may have following solutions:

a. Teaching students some certain rules of memorizing words: Prefix or suffix. For example, we meet the word "careless" in textbook for junior one. In junior two, we meet the word "jobless". Then, we may tell students that "-less" means not or without. Later on, when they meet some words ending with "-less", they can guess the meaning. Or they can memorize that according to the pronunciations. Compound words. For instance, blackboard, black and board.

b. Teaching students to pay attention to synonyms and antonyms. For example, black and white, careful and careless, poor and rich. Or, large and big, at once and immediately.

c. Teaching students to remember words by using them. The basic way to practise is to make sentences by given words. Only by using the words in certain situations, can students fully understand the meaning and be able to use them in correct ways.

Vocabulary in the language of a man ability development plays an important role, vocabulary size directly affect the ability of listening, speaking, reading and writing translation development, student's vocabulary, the bigger vocabulary on language students get, the stronger students input content of understanding ability, the higher students output language material quality. But usually, in learning a foreign language, students feel vocabulary is very difficult for them to remember, even remember a lot of words, when they use them, they can not either recall or error-prone. The vocabulary of insufficient or inaccurate is the "biggest obstacle" for each student who studies language during the process of learning. Aiming at the students' vocabulary learning of all kinds of confusion and error, we should get to the break- through point from learning in the daily teaching, to students' interest in study and life experience and cognitive level starting point of vocabulary teaching and paying attention to the coherence and layered, through experience, practice, participation and cooperation and communication ways of learning and task-based teaching approach, cultivating students' vocabulary actual operation ability, developing the students the comprehensive application capability of language, in lexical learning process, fully mobilize students' enthusiasm, initiative, the context to cultivate students' vocabulary learning accuracy and comprehensiveness. Meanwhile, according to the laws of YiBinHao forgotten, make constant resistance forget reappearance review. Through practice, this kind of vocabulary teaching project, taking the vocabulary teaching for English and course change of breakthrough point, the effect is very good.

\section{CONCLUSION}

As the writer mentioned above the paragraph, vocabulary plays an important role in language learning and teaching. Especially for students

In China, in order to get rid of the "traditional" shortcoming in English learning-dumb English and Chinglish, teachers may use more advanced ways to teach students understand words and expressions, most importantly, use them in a correct situations and make themselves understood by others.

\section{REFERENCES}

[1] Virginia French Allen. (2002). Techniques in teaching vocabulary foreign language education research center, Shanghai Foreign Language Education Press.

[2] Liu Juan. (2007). Vocational College English Vocabulary Teaching. The Introduction of Cultural Connotation Foreign Society in Fujian Province in east China and the Fourth International Conference on Foreign Language Teaching.

[3] CaoWuTang. (1996). the Concise English Lexicology. Jinan; Shandong Education Press.

[4] Ellis, R. \& Tomlinson, B. (1980). Teaching secondary English A Guide to the Teaching of English as a second language London: Britain Heinemann Education Press.

[5] Zhuang Zhixiang \& Su Dingfang. (1996). Modern Language Teaching. Shanghai Foreign Language Education Press.

Yingling Gu was born in Xinjiang Changji, China in 1958. She graduated from department of foreign languages in Xinjiang Normal University, China in 1998. She is currently an associate professor in Changji Radio and TV University, China. Her research interests include Language Teaching and Linguistics. 